Article published in the Journal of Social Welfare and Family Law. 2016. 38(4): 430-449 http://www.tandfonline.com/doi/full/10.1080/09649069.2016.1239362

\title{
Communication in Family Court: Financial Remedy Proceedings from the Perspective of Litigants in Person
}

\author{
Dr Tatiana Tkacukova \\ School of English, Birmingham City University, $U K$
}

\section{Communication in Family Court: Financial Remedy Proceedings from the Perspective of Litigants in Person}

The article presents a rationale for communicative, conceptual, cognitive and procedural challenges experienced by litigants in person in financial remedy proceedings. The article also explores oscillation between written and spoken legal genres and narrative development strategies which litigants in person have to use throughout different stages (from the early stages of starting proceedings, filling in court forms and providing documentation, through the negotiation process to interaction in court). While legal professionals express themselves in paradigmatic legal mode influenced by legal acts and legislation, litigants in person tend to express themselves in narrative mode similar to everyday storytelling. The objective is to investigate obstacles litigants in person experience during the process originally designed by legal professionals for legal professionals. The article evaluates different options for empowering lay people involved in legal proceedings and argues for the need to provide more specific support for different stages of family proceedings.

Keywords: litigants in person; communication; financial remedy proceedings; legal-lay discourse; communicative, cognitive, conceptual and procedural challenges.

\section{Introduction}

Access to justice is the right of every citizen but one that litigants in person (LiPs) find difficult to exercise. Due to cuts to legal aid in England and Wales since July 2013 
as a result of the Legal Aid, Sentencing and Punishment of Offenders Act 2012 (LASPO), civil courts are now struggling with an influx of litigants in person. The change is especially pronounced in family courts. Although the exact numbers of LiPs are not known, quarterly court statistic records show that cases with both parties unrepresented doubled in the first quarter of 2014 compared to the same period in the previous year (The Legal Aid, Sentencing and Punishment of Offenders Act 2012 (LASPO): One Year On, 2014, p. 69).

The most recent research-based reports reflecting on the impact of self-lawyering (The Legal Aid, Sentencing and Punishment of Offenders Act 2012 (LASPO): One Year On Final Report, 2014; Trinder et al., 2014) agree on the fact that litigation conducted by parties without legal representation will grow as a societal phenomenon and will continue to pose many challenges to courts and the justice system. As both reports suggest, many complex issues remain to be unresolved: the ambiguous role of McKenzie friends, the role of judges in providing sufficient guidance to LiPs, changes to rules and procedures to incorporate inquisitorial features into adversarial proceedings, imbalances in power relations in cases with domestic violence allegations and their funding, solicitors taking advantage of LiPs, LiPs making use of judges' sympathy to their circumstances. There is yet another level of complexities when additional problems arise due to LiPs' individual competencies and abilities, such as illiteracy, visual or auditory impairments, learning difficulties, non-native language competencies or other types of vulnerabilities (although they still have capacity to litigate without the need for a litigation friend). Although these complex issues do affect communication processes and access to justice, there are currently no standardised procedures on accommodating such needs.

The aim of the article is to illustrate conceptual, cognitive, communicative and procedural challenges LiPs face during financial remedy proceedings; the findings, nonetheless, apply to other types of family court proceedings as well as different areas of civil law. The focus is on financial remedy proceedings because of their relatively straightforward phases (especially in comparison to Children Act proceedings) and the clear financial advantages of representing oneself in cases where there is not much money to divide. The attempt to cut financial losses may present one of the reasons there seem 
to be more respondents in financial remedy cases than applicants as opposed to Children Act proceedings where the numbers for applicants and respondent in person are more balanced (Trinder et al 2014: 11-12). The other rationale behind the focus on financial matters is a more pronounced inquisitorial role of the court in financial remedy proceedings. The court has a duty to investigate matters in ancillary relief proceedings instead of being bound only by evidence submitted or arguments put forward by the parties (Black et al., 2014, p. 1316).

The study takes a novel approach to self-lawyering by stressing the significance of communication and interaction between the parties in private family law cases. Trinder et al. (2014, ch. 4) show that the prevailing expectation in family proceedings is that parties will try to settle. Any hesitation to negotiate from the LiP or opposing lawyer is negatively reflected in the outcome, length and overall efficiency of hearings. The underlying principles of trust and willingness to negotiate and arrive at a mutually amicable agreement are constructed linguistically, i.e. via language, communication and negotiation. The study therefore deals with communication in its widest sense (written and spoken communication, receptive and productive communication, interpersonal and institutional communication) as a link between lay and legal discourse types, narrativisation techniques and modes of interaction. The broad understanding of communication allows the concept to function as an umbrella term for conceptual, cognitive and even procedural aspects of self-representation. By providing the rationale for communicative complexities involved in self-representation, the article shows that lay people require clarity on the micro level of linguistic details as well as the macro level of court processes and procedures. The former aspect has been the focus of the Plain Language Movement and academic debate since late 1970s, whereas the latter one has long been disregarded in the academia and practitioner domain.

Court procedures are designed by legal professionals for the use of legal professionals. The Bar Council Report LASPO: One Year On (2014) states that the rise in LiP numbers is "unsustainable without wider reforms to make processes and procedures more transparent and accessible" (p. 59). Lack of experience of court processes and procedures together with the institutionally ambiguous role of LiPs create 
imbalances in power relations between parties in semi-represented cases, i.e. cases with only one party acting in person.

The mere presence of litigants in person introduces many imbalances in communicative processes, interaction patterns and power relations and thus influences the institutional roles of all the participants involved. Self-representation puts further constraints on the day-to-day management of courts, complicates CPR provisions, changes the role of the judiciary and influences even the role of the opposing party's legal representatives. For instance, according to the CPR in semi-represented cases the lawyers for the opposing party have to prepare and submit bundles, which financially burdens the represented party (Trinder et al., 2014, p. 76). LiPs' lack of experience or access to relevant information may further complicate matters and result in disruptive behaviour or non-appearances (ibid., p. 30).

This complex problem requires a comprehensive solution and effective communication and strategic engagement on different levels: local and national government level (e.g. full representation in cases with vulnerable LiPs, revising the readability and comprehensibility of HMCTS forms), official institutional level (e.g. providing signposting to the correct information and local sources of advice), interpersonal institutional level (e.g. training for judges on dealing with LiPs, such as offered by the Judicial College) and community level (e.g. increasing the availability of free advice and pro bono units). Effective and efficient communication is a necessary precondition for access to justice, a tool for all the participants involved and an achievement for the legal system.

\section{Research Objectives and Methodology}

The study draws on linguistic and socio-legal research in order to identify communication challenges for all participants involved in semi-represented and unrepresented cases during the entire litigation process. The article presents a qualitative analysis of spoken and written genres, narrative development techniques, interaction patterns and discursive strategies used during financial remedy proceedings, providing the rationale for LiPs' communicative challenges. The data for the analysis includes HMCTS forms, court instructions and witness statements as well as observations of three hearings and negotiations in the waiting room in between individual hearings (First Appointment hearing, Financial Dispute Resolution hearing and the Final 
hearing) of a semi-represented financial remedy case in family court in West Midlands in the period between September 2014 and April 2015. The observed case, in which the author shadowed an LiP, serves only as an illustration to contextualise the theoretical rationale for communicative needs of LiPs. This section presents the relevance of linguistic theories used for the study, i.e. genre analysis (language use in specialised context), narrative development (process of constructing master narratives for court), discourse analysis (underlying meanings in real life communication, identity construction and power in language) and conversation analysis (organisation of interactions).

The concept of genre is central to any professional communication. In simplified terms, genre can be defined as a "conventional, repeated and distinctive features of text that arise from its communicative purpose" (Coulthard and Johnson, 2007, p. 55). Bhatia (1993, p. 367) notes that even though genres are primarily conventional and conservative, they are nonetheless dynamic constructs. Genres are rarely presented in their pure forms; they often overlap and interweave with elements of minor genres embedded into a main genre. During police interviews, for example, police interviewers often oscillate between the genre of police interrogation and therapeutic genres in order to elicit the information more efficiently (Coulthard and Johnson, 2007, p, 61). Such functional hybridity (Coulthard and Johnson, 2007, p. 61) is common in legal genres because of the expectation that most communication would be underpinned by relevant legislation. During witness examination, for instance, counsel phrase their questions in a way which allows them to indicate whether particular aspects of a case fit the boundaries of the terms described in the legislation (Coulthard and Johnson, 2007, p. 58-59). For LiPs, cross-examination is thus a very challenging task because of its distinct generic requirements, power imbalances in the roles, discontinued narrativisation through a question and answer pattern and conceptual orientation to legislation (for more on crossexamination, see below at section 10).

Genres are closely interconnected with discourse, which is 'talk in interaction' (cf Heydon 2005: 14, Thornborrow 2002: 16) or 'language in use' (Brown and Yule 1983: 1). Some scholars use the term discourse as synonymous to communication (e.g. Heffer, 2005, p. 4). The most frequent understanding of the term discourse implies specific linguistic patterns which are co-constructed by recurrent contexts and communicational situations, written or spoken, and can be identified as different types of discourse (e.g. institutional discourse, legal discourse, discourse of legal documents). There is a variety of genres used in legal discourse 
ranging from judicial judgements, legislation in written form to lawyer-client consultation or counsel-witness examination in spoken form (Bhatia, 1993, p. 101).

The term discourse is often understood as an ideological process of creating meaning through social and power relations (Fairclough 1989). Language does not exist in isolation; the meaning is negotiated in the context of social and institutional roles, professional and organisational purposes and requirements or even cultural rules. A multi-perspective model of discourse covers all the relevant aspects: discourse as text, discourse as genre, discourse as professional practice, and discourse as social practice (Bhatia, 2004, p. 18). According to Bhatia (2004, p. 144), the process of acquiring discursive competence in professional and institutional settings involves gaining competence on three levels: textual competence, generic competence and social competence. Textual competence is the only function directly related to language as it incorporates linguistic competence (ability to use specialised language) and communicative competence (ability to both produce and interpret contextually relevant texts). Generic competence is the ability to produce and interpret generic conventions of professional cultures and practices to achieve specific professional aims (e.g. producing a well-organised and coherent witness statement meeting all formal requirements). Social competence is the ability to communicate effectively in social and institutional contexts and thus define one's social identity and institutional role (e.g. effective negotiation strategies). The last two aspects are to a large extent dependent on non-linguistic competence and changeable circumstances; but these competencies are reflected in the linguistic performance and therefore reflect on the ability to contribute to the discourse and accomplish professional aims. Bhatia (2004, p. 148) also states that acquisition of professional expertise involves four categories: education and knowledge; training and experience; the above-mentioned discursive competence; and discursive practice (i.e. ability to choose the relevant genres for achieving professional objectives in the professional context). For lay people in financial remedy proceedings, there are therefore many unknowns involved in the preparation of such text genres as a chronology or questionnaire since they would first have to find out what information is relevant (lack in knowledge), what the outlay is or how to phrase the questions (lack of discursive competence and discursive practice), and then foresee the role of these documents in the overall course of the proceedings (lack of experience).

Another important concept for this article is that of power and control exercised through language in institutional and professional discourse types. As a process which is activated 
through every level of social interaction, power is attributed to the participants in talk according to their institutional identity, social status or gender (Thornborrow, 2002, p. 7). Power is thus manifested as different types of social and factual constraints (Fairclough 1989, p. 74). Power asymmetries in institutional discourse arise due to question/answer patterns of interaction, different amounts of knowledge shared by the participants, and the perception of a client's unique case as a routine situation (Drew and Heritage, 1992, pp. 47-51). According to Thornborrow (2002, p.16), in practice power in language is analysed through social relations (e.g. control over the interactional space, turn-taking, topic management, formulation of facts, modality, politeness features) and social reality (e.g. cohesion, lexical choice, metaphorical meanings). What is equally important is that asymmetry is an inherent, justifiable and fully functional aspect of institutional discourse (Pilnick and Dingwall, 2011). Asymmetrical interactions help create orderliness to meet institutional requirements (Atkinson, 1982). The ambiguous institutional role of LiPs (they are clients and their own advocates in one but viewed as lay people by judges and opposing counsel), nonetheless, means that they do not have as much control over interaction in court as counsel. For instance, in semi-represented cases judges may want to start discussing matters first with the opposing counsel, which makes interaction asymmetrical in favour of the represented party.

In summary, this article aims to contribute to current debates on access to justice by illustrating the role language and communication play in theory and practice in financial remedy proceedings.

\section{Linguistic research on self-representation}

The phenomenon of self-lawyering is an important societal issue, but it is notably under-researched as a scientific topic. This is in part because research into legal-lay communication lies at an intersection of linguistics and socio-legal studies, and few researchers possess the requisite skills in both. In fact, neither of the disciplines has devoted due attention to the topic.

Research directly dealing with linguistic aspects of litigation in person is limited to two short studies on small claims courts (O'Barr and Conley, 1990; Conley and O'Barr, 1998) and research conducted by the author (Tkacukova, 2010, 2011, 2015). The first two studies deal with narrative devices used by self-represented litigants in the USA and conclude that lay people present narratives common in everyday conversations and 
therefore produce relational accounts instead of rule-oriented accounts required for the purposes of courts (e.g. self-represented litigants describe their feelings instead of limiting themselves to relevant facts). This is in line with Heffer's (2005, pp. 20-24) observation of the tension between the paradigmatic (socio-scientific) mode of reasoning and the narrative mode of reasoning in courtroom discourse. While legal professionals are trained in thinking and expressing themselves in the paradigmatic mode based on logical argumentation and legal principles, lay participants employ the narrative mode similar to everyday storytelling. Moorhead and Sefton (2005, p. 154) show that there is a risk of LiPs misconstruing their claims and expressing themselves in non-legal terminology, which is difficult for judges to interpret. Trinder et al. $(2014$, p. 24) found that there is no clear link between educational and professional background and the ability to self-represent, as even highly educated or professional litigants struggle with identifying legally relevant issues or following relevant court procedures. What seems to have more impact on the capacity to self-represent is previous experience with legal proceedings and being represented (p. 83). The well-established theory of situated learning in cognitive psychology and education studies recognises that the individual's participation in goal-oriented activities and first-hand experience with the authentic situation and social circumstances constitute the basis for learning and cognition (Billett, 1996, p. 263). We learn by experiencing the process from its beginning till the final stages, which allows us to reflect upon the experience, gain feedback and gradually acquire the skills through further practice. This is the reason many repeat LiPs feel that their previous experience with being represented is very helpful as they understand the process and procedures better (Trinder et al., 2014, p. 83).

Tkacukova (2010) argues that in long proceedings, litigants in person develop an inter-genre and additional competence as the hearings progress, comparable to second language learners who develop an interlanguage as they acquire a new language. Similarly, Trinch (2005) reports on protective interviews with victims of domestic violence of Latina origin who have to adapt their language to the genre of report when interacting with legal professionals. The author's conclusion is that lay women develop an inter-genre only to a very limited extent. Tkacukova (2010) states that without professional assistance or support, LiPs' capacity for gradual development remains unstable. 
The author's studies (Tkacukova 2008, 2010, 2011) on cross-examination conducted by LiPs show that lay people find it challenging to adapt their interactional habits and language use to the hostile atmosphere and asymmetrical question/answer interaction during crossexamination. LiPs use too many open questions instead of leading questions and support witnesses instead of challenging them. This influences the role of judges who often have to explain common legal concepts, such as 'evidence', 'opening speech', or 'cross-examination' to lay people. In Tkacukova (2015), the most frequent function judges performed when talking to LiPs was to provide explanation or suggestions on procedural matters and legal concepts.

Despite the pioneering nature of the above-mentioned linguistic studies, they are limited in the scope of features analysed, type and number of cases. They also focus solely on spoken discourse during courtroom proceedings. Although interaction in court is a very challenging stage for LiPs and certainly an under-researched area, in practice LiPs are not expected to be as skilful and articulate as legal professionals when presenting their cases. From the perspective of legal practitioners, it is the pre-hearing stages (filling in forms, deciding on the strategy, collecting evidence, providing supporting documentation and negotiating many legal and procedural aspects with the other party) that have the most impact on the outcome of the proceedings. Effective communication (written and oral) plays a key role in pre-hearing preparations, which involves language use on different levels, starting from the semantic level (use of legal terminology and concepts) to that of discourse (use of legal genres, e.g. writing witness statements). When in court, it is too late to change the strategy or introduce new evidence and there is little judges can influence at this stage.

Key features of legislation and legal proceedings are constructed linguistically. Involving linguists in reviewing pre-hearing stages (e.g. HMCTS forms) or reflecting upon different stages of proceedings can therefore help facilitate communication between lay people and legal professionals and increase access to justice. For instance, the introduction of regulated intermediaries to assist vulnerable victims is a very good example of effective involvement of professionals in legal proceedings to ensure unimpeded communication (http://www.theadvocatesgateway.org).

\section{Socio-legal research on self-lawyering}

Research on litigation in person within socio-legal studies is equally scarce and fragmented. It touches upon challenges faced by LiPs and court administration, the role of judges in unrepresented or semi-represented cases, and potential options for improving 
LiPs' access to justice (ranging from simple adjustments of the language in court correspondence to more profound reforms). The full picture unifying different aspects of self-representation across different areas of law is however lacking.

The recent comprehensive report on LiPs by Trinder et al. (2014) focuses on family law, but it can serve as a good indication of overall difficulties lay people have with other areas of law as well. The report (Trinder et al., 2014, ch. 5) shows that LiPs face different types of challenges and there are no easy solutions to overcome them. LiPs are disadvantaged from the very beginning of the proceedings because of fundamental deficiencies in their skills or knowledge: lack of knowledge of relevant substantive issues in their case; unfamiliarity with litigation process and court procedures; difficulties with understanding important concepts, such as the importance of disclosure or the expectation of negotiation and settlement. In addition to these complications, lay people may lack organisational skills (e.g. managing deadlines), technical skills (e.g. conducting cross-examination, compiling documents for court bundles, preparing evidence and witness statements) or have other types of personal vulnerabilities (mental health problems, domestic violence, low levels of literacy or low command of English, etc).

Difficulties faced by lay people inadvertently complicate the role of the court staff, the other parties' legal representatives and judges. Cases with LiPs were found to take longer and were less likely to settle than fully represented cases (Moorhead and Sefton, 2005, pp. 257-258). The average length of shorter procedural hearings in fully represented cases was comparable to the length of cases with LiPs (Trinder et al., 2014, p. 56). Substantive hearings were, however, longer in unrepresented or semi-represented cases because of the time required for the judge to explain the process to lay people.

Trinder et al. (2014, ch. 4) identified four circumstances of working hearings in family court: (1) an opposing lawyer in a semi-represented case acting non-adversarially; (2) a third party, a Cafcass officer or a children's lawyer, identifying positions between the parties and negotiating; (3) a fully inquisitorial judge proactively looking for solutions; (4) a responsive LiP active in the process offering focused contributions, reacting appropriately to judicial prompting and signposting, and cooperating with the opposing party's lawyer. The active involvement of a legal professional or judge and the non-adversarial adaptation of the process thus play significant roles in effective hearings. The report published immediately after the cuts into legal aid were introduced, The Judicial Working Group on Litigants in Person: Report (2013, p. 8), advocates a more 
inquisitorial form of process in semi-represented and unrepresented cases, but it does not mention what exactly this would entail. Trinder et al. (2014) describe features of working hearings led by a fully inquisitorial judge as follows: (1) judge-led agreement-seeking process in directions hearings and (2) strong steering of the case and taking over crossexamination in substantive hearings (pp. 62-63). A slightly different approach, an enabling approach to LiPs, has a long tradition and is well-documented in tribunal hearings (e.g. Legatt, 2001; Adler 2008 quoted in Fielding, 2010, p. 130). It is based on the idea of judges providing a supportive environment for LiPs and actively guiding them through the hearings. From the legal perspective, the differences between the enabling approach and inquisitorial features have not been explored yet.

Zuckerman (2014, pp. 360-361) argues that the inquisitorial system cannot offer any reliable solutions for current challenges facing the adversarial system with unrepresented cases. In inquisitorial proceedings, legal presentation is compulsory (with the exception of minor small claims cases): the technical and formalistic nature of European systems does not envisage self-representation as an option. The court thus heavily relies on legal representatives in investigating the case, outlining relevant legal issues and determining which matters need to be further examined (Zuckerman, 2014).

Zuckerman (2014) also warns that if judges were to be involved in the investigation process, they would be exposed to unconscious and unintentional confirmation bias. A wellfounded theory of cognitive psychology shows that people tend to favour their pre-existing beliefs and are thus less receptive towards alternative evidence. Being involved in the investigation process would put judges in a difficult position: and background assumptions unconsciously influence the decision-making process, which would lead to compromising their judicial objectivity (pp. 362-363). Additional numerous complications can arise during witness examination: (1) it would not be possible to bring a professional witness (e.g. psychologist) to testify and (2) conducting cross-examination would be difficult as judges cannot take instructions from a party, nor can they offer legal advice on cross-examination strategies. In serious and complicated cases with rape or domestic violence allegations where an alleged perpetrator is unrepresented, the question of who should cross-examine the victim causes a serious concern for the justice system (Zuckerman 2014, Sommerlad 2015). Another aspect to consider is the variability and variety in judicial styles, which needs to be dealt with in any future reforms (Trinder et al., 2014, pp. 50-51). Both the variability in the judicial style and 
that of opposing lawyers complicate the fact that currently court processes and procedures have not been adapted to the needs of LiPs.

Whereas the focus of research on self-lawyering in England and Wales is mainly on the consequences of cuts into legal aid and regulation of the legal profession, in Canada and the US there is more focus on the individual experiences of self-represented litigants with several initiatives to support lay people in a variety of ways. In California, for instance, there is an extensive self-help programme run by the Centre for Families, Children \& the Courts of the California Administrative Office of the Courts. The Centre offers a range of services for selfrepresented litigants, develops family law forms, rules, procedures and guidance for judges and incorporates different practice-based solutions into policy making (http://www.courts.ca.gov/programs-cfcc.htm). According to Mather (2003, p. 150 quoted in Trinder et al., 2014, p. 21), in the US self-representation is supported on the institutional level through the simplification of court procedures and comprehensive provision of assistance. In Canada, a local initiative, the National Self-Represented Litigants Project, provides training, advice and psychological support for self-represented litigants. A comparative study between different jurisdictions could bring useful suggestions and help exchange best practices and solutions.

On the international level, due to the Brussels Convention on Jurisdictions and the Enforcements of Judgements in Civil and Commercial Matters 1968 and Brussels II bis Regulation 2003 for divorce proceedings, parties can resolve legal disputes in a member state and enforce judgements in another member state. Although this makes it easier to dissolve relationships abroad, the national legislations and regulations differ, which could present a problem for lay people even when represented. The complications naturally multiply if acting in person and possibly even facing language barriers. This issue presents yet another topic to be further explored.

\section{Existing sources of information}

The legal market and profession have adapted to the post-LASPO challenges in a number of ways: an increase in preparing handbook-type publications by official bodies (e.g. A Guide to Representing Yourself in Court by the Bar Council, A Handbook for Litigants in Person by HHJ Bailey et al.) and individual practitioners (e.g. Reed, 2014); an increase in online support offered for LiPs (e.g. Wikivorce website or previously existing website 
AdviceNow); a rise of alternative business structure licence holders (e.g. Co-operative law); provision of support centres with limited geographical coverage (e.g. Chancery Litigants in Person Support Scheme or previously existing schemes such as Royal Courts of Justice Advice Bureau or Personal Support Units for non-legal advice). Although these support strategies offer more options and more personalised routes to justice for LiPs, they do not deal with the basic communicative challenges lay people experience (e.g. how to prepare an effective and credible witness statement that would otherwise be revised by a solicitor). Likewise, these remedial options do not go to the core of the problem, e.g. courts' institutional communication and the easing of court procedures.

Unless LiPs have financial means to pay for legal advice in the early stages of the proceedings, they are often left to their own resources when searching for more information and deciding on the strategy. Trinder et al. (2014, pp. 89-91) report that LiPs struggle finding the right information since official HMCTS or MoJ web pages are not tailored for the needs of lay people and thus fail to provide clear information about court processes. Accurate information on legal issues relevant to specific cases is even more difficult to gain. None of the respondents knew about the official DWP web site Sorting out Separation and found other online sources too general or biased because of the specific agenda of the contributors. Furthermore, not all LiPs have access to the internet or are computer-literate, which further complicates access to the information.

The more traditional ways of acquiring information on court process from courtroom staff or receiving free legal advice from pro bono centres or Citizens Advice Bureaux $(\mathrm{CAB})$ are equally complicated and inaccessible. In many courts across the country, face-to-face court counters were discontinued or limited in availability due to financial cuts. The number of PSU offices, where volunteers can provide help filling in forms and explaining the process and procedures without providing legal advice, is also limited. Pro bono representation is very scarce and the fact that there are only four CABx in England and Wales offering advice in family law clearly shows that the demand far exceeds the supply of services (Trinder et al., 2014, p.91-92). Sommerlad (2015) warns that due to cuts in legal aid and law firms collapsing, "advice deserts" may form, i.e. areas without any professional legal advice available. The author also mentions that without the legal aid finance, law firms are now offering cheap services by poorly qualified and less experienced professionals. Maclean's study on the diversification and 
unbundling of legal services (2014) shows that self-help packages, supported by seeming "professionals" without clear identification of their qualifications, could help in unproblematic uncontested divorces. But when it comes to fully contested proceedings, there do not seem to be any affordable services.

Without easy access to reliable information, lay people cannot fully participate in the legal process. Lack of knowledge can result in deepening the severity of their lack of discursive competence, practice and experience.

\section{Procedural challenges and institutional communication}

Procedural challenges present the first obstacle LiPs have to overcome when starting proceedings. These involve difficulties with court process and procedures, such as choosing the right forms and filling them in, paying the right fee, finding out how to submit documents, etc. There are further technical and strategic tasks, which pose more advanced problems: what documents to prepare, what the purpose of direction hearings is, how to prepare for court hearings and negotiate with the other party, how to present arguments, write witness statements, prepare bundles, submit forms and additional documents to court, bring a McKenzie friend to court, etc.

Misunderstandings about the court process are one of the most problematic areas LiPs struggle with (Professional Conduct Department Thematic Review, p. 9). Williams (2011, p. 6) reports that the main contribution lawyers brought to the outcome of cases in Sanderfur's study (2011) was connected essentially to their extensive knowledge of procedures; their knowledge of substantive law was not a decisive factor. Williams (2011) concludes that the presence of a lay representative familiar with procedures may be as effective as representation by a professional (p. 7). Trinder et al. (2014, p. 79) found that LiPs mostly required information on process and procedure along with emotional support and specific legal advice.

Given the reported information needs of LiPs, the institutional communication on procedures and process on official web sites (choosing the right form, paying the right fee, stages of proceedings, etc) and any court communication (what to expect, where to find information, legal help and support) should be clear and easily available. Clear instructions and straightforward communication on the official level will send positive signals to lay people and encourage them to actively participate in the proceedings and self-represent (Trinder et al., 
2014, p. 21). A user-friendly approach would benefit not only LiPs but also represented clients and help them avoid any misunderstandings with their lawyers.

\section{Legislation and institutional communication}

Legislative writing has long been known for its obscure and highly complex language, terminology and sentence constructions. To serve its communicative purpose, legislative writing needs to be precise and unambiguous. Bhatia (2004 ch. 5) lists the following linguistic features of impersonal and decontextualised legislative writing: nine times longer sentences than in academic writing (Bhatia, 1993, p. 106); nominal phrases (e.g. 'treatment' instead of 'to treat'), prepositional phrases (e.g. 'by virtue of'); binominal and multi-nominal expressions (e.g. 'an accused person has accepted or obtained, or has agreed to accept or attempted to obtain'); initial case descriptions prolonging the subject; qualifications specifying conditions in which the provision applies; syntactic discontinuities. The Plain Language Movement and its UK-based offshoot, the Plain English Campaign, have been advocating for increasing readability of institutional communication, including legal language, since the 1970s. Assy (2011, p. 378) argues that the ideals of the Plain Language Movement are unachievable due to the complexities of the reality it has to depict. The author also states that by simplifying language, law will not automatically become intelligible to lay people. The ability to understand legal concepts goes beyond the mere simplification of the language and involves such skills as "the ability to identify the pertinent legal rules, principles, and doctrines, to recognize the relevant facts and classify them into the pertinent legal categories, and to engage in a particular type of interpretation and reasoning" (Assy, 2011, p 378). This resonates with what has been mentioned in section 2: effective involvement in the legal process is dependent not only on language and passive understanding, but on discursive competence and practice. Bhatia (2004, p. 209) notes the psycholinguistic challenges legal language presents to lay readers in terms of processing and comprehension, stressing that simplification of the content or form is not advisable due to the complex nature of the reality legislative documents aim to reflect. Instead, Bhatia talks about easification of documents to improve the processing of the text by the wider specialist public without losing the original integrity of the text. This means that the easified version would still require another simplified version for purely explanatory and educative reasons for the wider audience. Easification devices include clarification of cognitive structuring, reducing information load at a particular point, indicating legislative intentions, and illustrating legislative issues (Bhatia, 2004, pp. 209-218). 
Due to the fact that family law is one of the most widely used areas of law, the accessibility and comprehensibility of the relevant legislation should be a priority. Yet there are many complexities in the current version of the Matrimonial Causes Act 1973 which could be avoided. An online version of the Matrimonial Causes Act 1973 includes many genre obscurities characteristic of laws and acts. Linear reading and text coherence are obstructed by multiple annotations referring to different parts of the Act, modifications of the information and amendment of textual nature. There are also outstanding changes not yet available in the printed or even online versions, which are listed separately. The extract below from section 25 of the Matrimonial Causes Act is linguistically and cognitively complicated:

Section 25 (1) It shall be the duty of the court in deciding whether to exercise its powers under section 23, 24 [F47, 24A or 24B] above and, if so, in what manner, to have regard to all the circumstances of the case, first consideration being given to the welfare while a minor of any child of the family who has not attained the age of eighteen.

There are several levels of complexities in the text: lexical, syntactic and textual. The text could be easified on the lexical level without losing any important legal information (e.g., 'a minor of any child of the family under the age of eighteen' or 'a child of the family under the age of eighteen' instead of the original 'a minor of any child of the family who has not attained the age of eighteen'). Dividing the sentence into two sentences will make the intention of the MCA stand out, which is the welfare of children under the age of eighteen:

Section 25 (1) It shall be the duty of the court in deciding whether to exercise its powers under section 23,24 [F47, 24A or 24B] above and in what manner to have regard to all the circumstances of the case. The first consideration will be given to the welfare while a minor of any child of the family under the age of eighteen.

Shortening the sentences will result in clarified cognitive structure and reductions in information load at one point. The density and complexity of legislative and statutory writing is justifiable by the need to answer legal questions and clarifying the intention but the discontinuities in the coherence of the text pose many problems for lay readers, who are frequent users of family law. Assy (2011) argues that the rhetoric of plain language that legal writing should aim to reach lay readers so they would not require the assistance of a legal professional is misleading. But the author does accept that plain language can assist represented litigants and lawyers in interpreting statutes and legal texts (Assy, 2011, p. 383). Similarly, this article argues that easification of legislative writing can help not only LiPs, but also represented 
litigants and legal professionals as a more user-friendly version can assist in communicating complex issues during lawyer-client discussions.

\section{Institutional communication: court forms and court correspondence}

HMCTS forms and court correspondence with instructions present an important pillar in institutional communication. Forms elicit information relevant to the underlying legislation and their language is thus derivative of the legal principles. But whereas with legislation a strong argument can be made in favour of complexities allowing for more precision in the text, court forms are filled in by lay people and thus need to be easily understood by them. Even choosing the right form can be challenging: there are several forms $\mathrm{A}$ and $\mathrm{E}$ and finding out which form to use or what fee to pay requires access to internet, computer-literacy skills and familiarity with the system. The recent Report of the Financial Remedies Working Group (2014) envisions changes in the near future and, for instance, unifying forms E. It is not clear though whether the language will be easified. The report however proposes preparing supporting guidelines for financial remedy proceedings in several languages.

Below is the first paragraph of the current Form A revealing ambiguities in coherence and syntactical constructions (it is worth noting that Form A has already been revised several times):

Please note you must have previously filed a petition for a matrimonial or civil partnership order before completing this form. This form should only be completed if you are applying for one of the financial orders shown against the tick boxes below. If you are applying for a financial remedy other than a financial order in the Family Court please complete Form A1, unless you are applying for:

- financial relief after overseas divorce/dissolution under Part 3 of the Matrimonial and Family Proceedings Act 984/Schedule 7 to the Civil Partnership Act 2004 (please complete D50F)

- financial provision under section 27 of the Matrimonial Causes Act 1973/Part 9 of Schedule 5 to the Civil Partnership Act 2004 (please complete D50C)

- alteration of a maintenance agreement under section 35 of the Matrimonial Causes Act 1973/paragraph 69 of Schedule 5 to the Civil Partnership Act 2004 (please complete D50H) 
The very first sentence with the construction 'must have previously filed' is on the level of very advanced language users and could cause problems to second language speakers with up to upper-intermediate proficiency. The third sentence contains two subordinate clauses ('if' and' unless' subordinate clauses with the main clause 'please complete Form A' in the middle) and double negation ('other than' and 'unless'). The structure of the second sentence is thus too ambiguous: the sentence is difficult to comprehend for someone filling in the form for the first time, irrespective of their first language or education. Furthermore, the bullet points contain mainly meta-text information, which will not be clear to lay people. The web site from which all forms are available (http://hmctsformfinder.justice.gov.uk) does not provide any guidance on filling in forms or explanation of legal concepts. Lay people are thus likely to face many comprehensive challenges with the chosen excerpt. What is more, their lack of discursive competence and practice may stop them from ticking all boxes in the form. Lawyers tick boxes for all orders in case of unexpected circumstances arising during the proceedings.

Trinder et al. (2014, p. 105) specifically state that priority should be given to re-drafting all communications, including forms, leaflets, signage, etc. For instance, court instructions sent out before the First Appointment hearing at Birmingham Family Court contain a list of forms to be filled in, including Form G and Form H. But neither of the forms is easily searchable online under the letter-abbreviated titles. It is easier to find the forms under their full titles, i.e. Form $\mathrm{G}$ is Notice of Response to First Appointment and Form H is Estimate of costs (financial remedy). Including more specific information and signposting LiPs to relevant sources of information could help lay people and courts avoid misunderstandings and send a positive message to the users of the court system.

Closer interdisciplinary cooperation with linguists and communication experts would bring more clarity to HMCTS forms and court procedures and processes. A good example of such cooperation is a current pilot project of the PSU Birmingham at Birmingham Civil Justice Centre. The pilot project introduces a simplified form under the title 'Application for help with fees' instead of the existing HMCTS form 'Application for a fee remission'. As evidenced in the title, the form contains simple plain language, the information load at one point is reduced significantly, the font is bigger and individual sections are shorter. The PSU Birmingham has had positive feedback from its clients filling in the form as well as court staff dealing with fee remissions. 


\section{Presenting cases through a variety of genres and modes of communication}

One of the features of everyday conversation is storytelling; narrativisation also plays an important role in the adversarial legal system and courtroom genres. But legal narratives are much more complex due to the strong goal-oriented and persuasive nature of trials (Cotterill, 2003, p. 24). In criminal proceedings, there are master narratives counsels base their cases on and satellite narratives that are being told by witnesses (Snedaker, 1991 quoted in Gibbons, 2003, p. 155). Master narratives are thus formed gradually through satellite narratives. In family proceedings, there is special emphasis on pre-hearing stages with the presumption that most cases will be settled without the need for the final hearing (Trinder et al., 2014). Master narratives in financial remedy proceedings are formed by written satellite narratives (elicited through court forms, questionnaires, chronologies, statements of issues, witness statements) as well as oral satellite narratives of witness testimonies in court, negotiations, etc. Master narratives are thus multi-perspectival (Cotterill, 2003, p. 25) and narrative construction goes hand-in-hand with 'narrative disjunction' (Coulthard and Johnson, 2007, p. 111). For lay people the fragmentary nature and nonlinearity of narratives presents a challenge because without the prior experience of the proceedings, it is difficult to foresee the development of satellite narratives. The satellite narratives of LiPs are thus created for individual stages and may not fit well into the master narratives, which may then require the readjusting of what had been previously presented. Needless to say, inconsistencies in presenting facts make LiPs look less credible.

Another challenge is presented by the fact that satellite narratives often progress in between written and spoken genres of communication. Figure 1 shows the diversity of genres and media of communication used in court: 


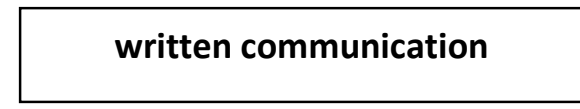

spoken communication

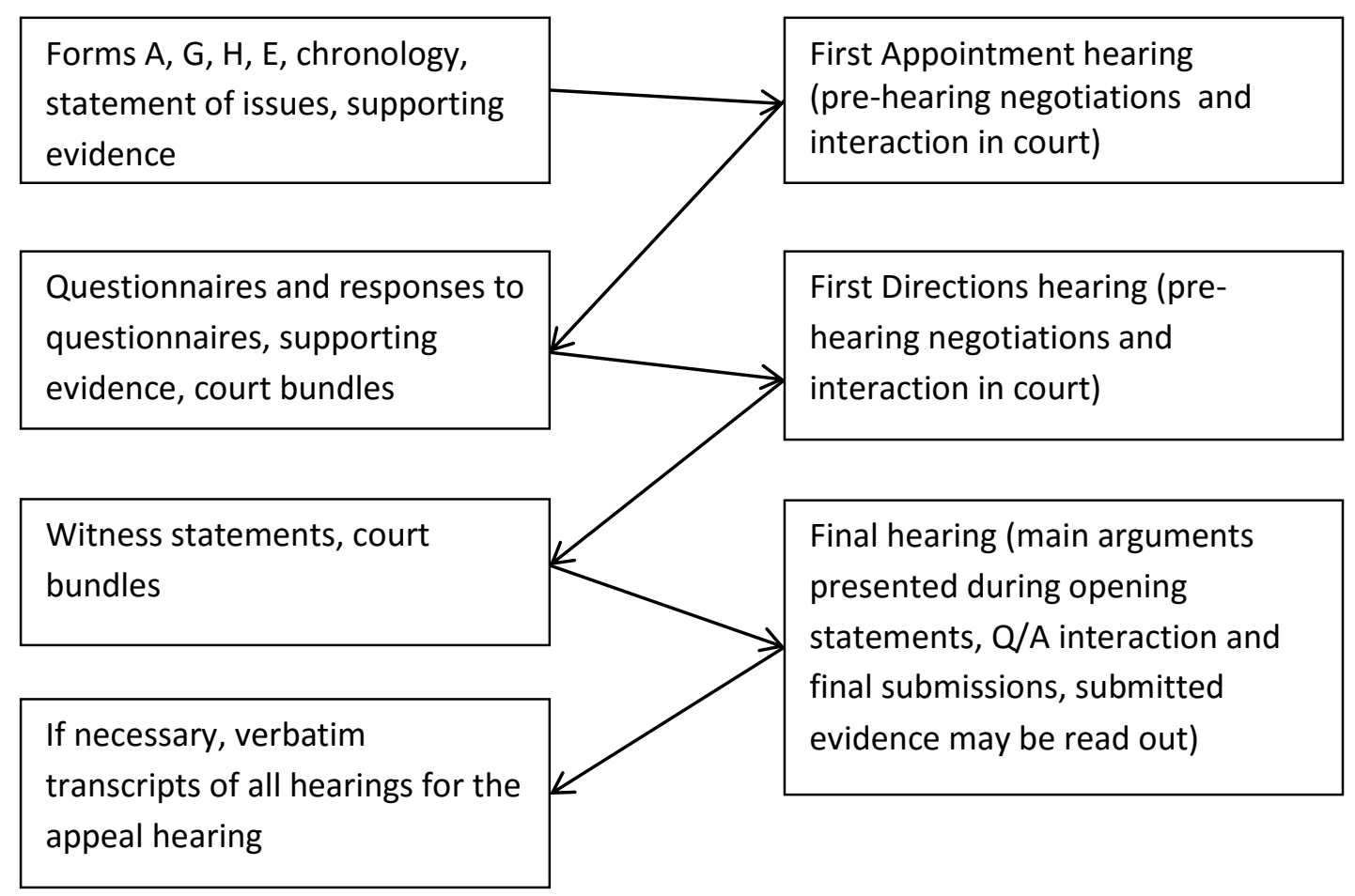

Figure 1: Conversion between spoken and written media of communication during financial remedy proceedings.

Lay people lacking in discursive practice or experience may struggle with the fact that the same satellite narratives are being retold and re-contextualised in different genres and modes of communication. Some of the genres are more open and require more work on the structure, wording, legal and textual coherence. Figure 2 shows the progression of the genres used in financial remedy proceedings from eliciting restricted narratives (e.g. forms) and semirestricted narratives (e.g. responses to questionnaires) to open narratives (e.g. witness statements) in both written and spoken forms: 


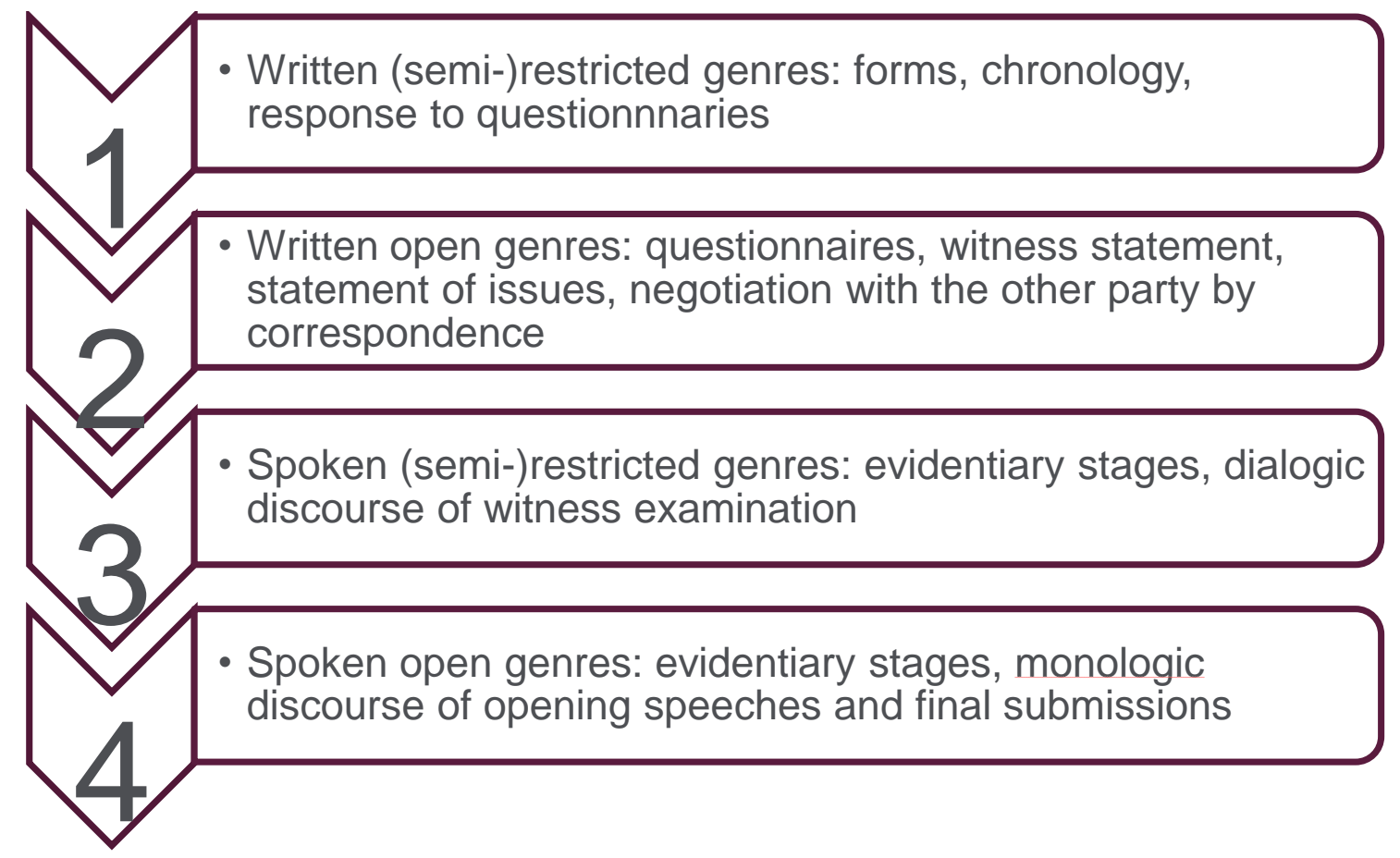

Figure 2: Genres used during financial remedy proceedings.

Preparation of opening genres requires more support and guidance. As reported in Trinder et al. (2014), some LiPs are not computer literate or do not have access to a computer or internet. The author herself has observed litigants preparing and sealing hand-written witness statements in the drop-off box in Priory Courts in Birmingham. With support from PSU and online information (e.g. AdviceNow), it is easier to fill in court forms and other documents of semi-restricted genres. But open genres are not so straightforward. A well-prepared written statement, for instance, needs to have all the genre specific features (e.g. names of parties and case number, statement of truth, numbered paragraphs, numbered pages), contain legally relevant information presented in a coherent way (e.g. outstanding debts, equity in the FMH, change to income/outgoings, future housing needs) and refer to the evidentiary documents attached to it (e.g. bank statements, mortgage statements). It may be argued that Form E provides the above-mentioned types of information, but if required, the witness statement needs to build-up on the Form E and present a coherent and logical narrative to support the case. Given that LiPs sometimes do not know what evidence is relevant to their case and may lack access to tailored legal information (Trinder et al., 2014), open genres can present a real challenge. Similarly to foreign language acquisition, genre acquisition is a long process that requires contextualised learning and feedback (Tkacukova 2010). The problem is that without professional legal help, LiPs do not have a chance to receive feedback on their witness 
statements or re-submit them to court. Official templates for open genres with suggestions on types of evidence to include or different types of hearings would provide a useful resource to LiPs.

\section{Power relations}

The previous section presented the rationale for challenges lay people experience with written genres. Similarly to satellite written narratives, open oral narratives also present challenges for LiPs on several cognitive and communicative levels. But in spoken institutional interaction the imbalance in power relations further complicates the communicative process. This section illustrates how the institutionally ambiguous role of LiPs and their lack in discursive practices and experience disadvantages them during cross-examination, interaction in court and waiting room negotiations with the other party.

Cross-examination is about testing satellite narratives by discrediting the witness as a person or their presentations of facts. The question/answer interaction pattern creates narrative disjunction (Gibbons, 2003, p. 158; Coulthard and Johnson, 2007, p. 111) and presents an artificial communication style for lay people because the reason for asking questions is not to find out answers but to present a more favourable interpretation of facts. There are numerous manuals on cross-examination techniques for beginner lawyers since professionals learn questioning skills through training and experience. Presenting or challenging the narrative through the question/answer interaction pattern is a challenging task for anyone lacking in discursive practice or experience.

Figure 3 illustrates what discursive tools cross-examiners use to control all aspects of cross-examination including witnesses' replies and the judges' perception of the information presented. 


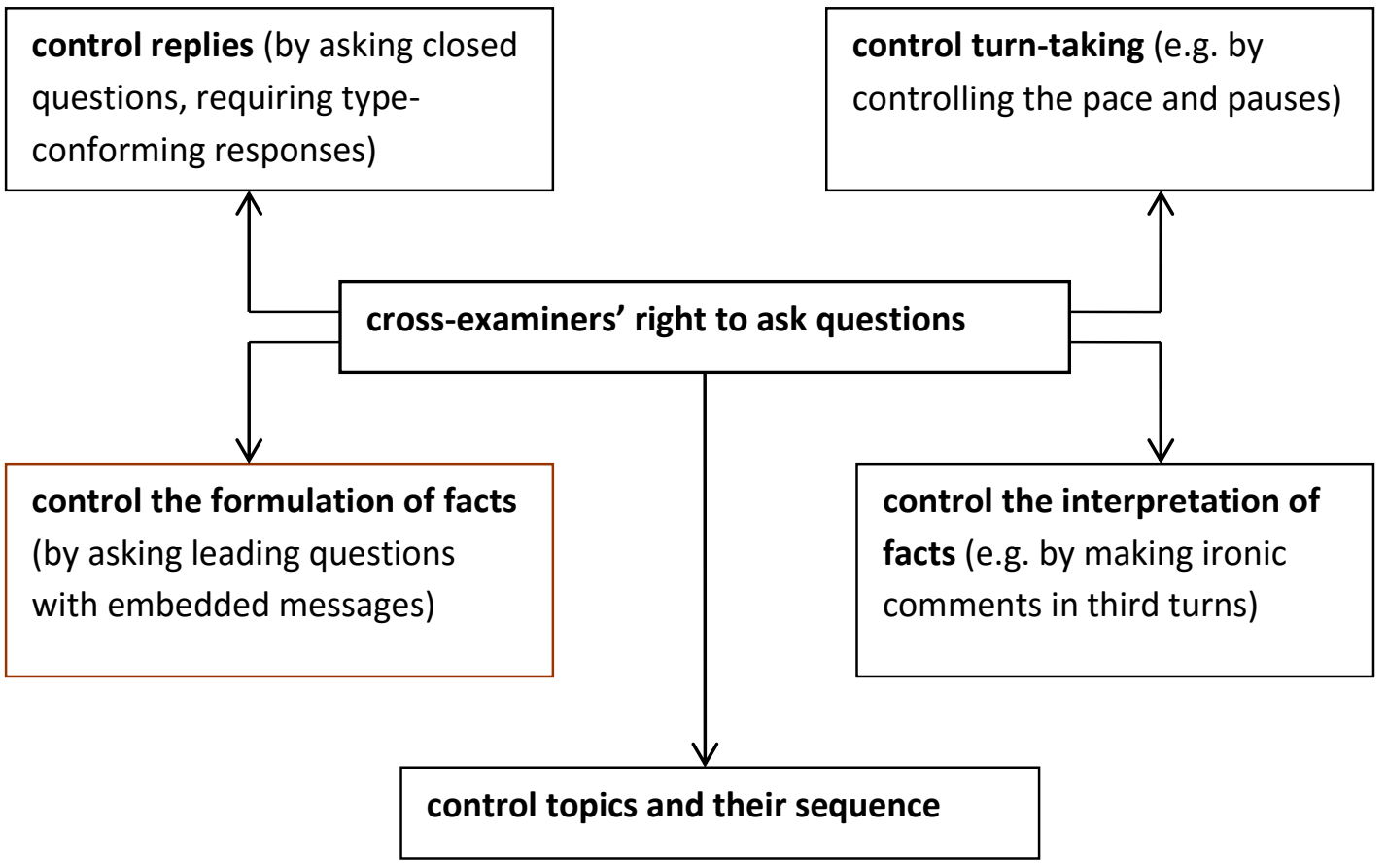

Figure 3: Discursive tools used by cross-examiner to control witness replies.

The right to ask questions is an opportunity for cross-examiners to control replies and limit witnesses to a position of having to provide answers (Heydon 2005: 115). Counsel restrict witness replies by asking closed questions (e.g., 'You saw him?', 'You saw him, didn't you?', 'You saw him, is that right?'), which forces witnesses into providing minimal replies ('Yes/No' replies). If, for instance, a witness does not want to answer a yes/no question with a minimal response, the cross-examiner's institutional right to require type-conforming responses allows them to request a witness to do so through the judge or to treat the witness as non-responsive (Raymond 2003: 957). Leading questions are yet another powerful tool for controlling the formulation of facts.

Witnesses are also left without the right to suggest new connections since crossexaminers control the topics discussed and even their sequence (Wang 2006: 541). Even if witnesses are asked to add something at the end of cross-examination or if they are reexamined, the confusing and stressful experience in the witness box may cause them to miss an opportunity to tell their story in a coherent way. In addition, control over turn-taking enables cross-examiners to violate the normal length of pauses between the questions and make use of a deliberately fast pace of questioning or prolonged pauses in order to stress or dramatise facts (Gibbons 2003: 117). Cross-examiners even have an opportunity to control 
how the audience should interpret responses by commenting on witness replies in an ironic/sarcastic manner (Gibbons 2003: 124-125).

These strategies are used to test the other party's narrative and present your narrative through questions. Lay people, however, struggle with cross-examination. Tkacukova (2010) shows that LiPs give cross-examined witnesses too much interactional space by asking them open questions or questions which do not restrict them in their replies. One of the examples the author reports upon is when an LiP asks an expert witness to state any professional qualifications and affiliations the witness has, giving thus the expert an opportunity to present his credibility. A professional counsel would only have done this if there was an opportunity to show that the witness was an expert in the appropriate field, for instance.

The institutionally ambiguous role of LiPs can also be observed during communication in court. The author observed a judge start to discuss issues in a case with the respondent's solicitor instead of the LiP who was an applicant. In these discussions about the equity in the property abroad, the respondent's solicitor presented an exchange rate which was favourable to his client and this was noted down by the judge. The applicant LiP did not receive an opportunity to present a more favourable exchange rate on their own behalf and was not confident enough to raise this point with the judge. In the other two hearings observed by the author, the judge started by explaining procedures to the LiP and stating that there would be an opportunity to come back to the LiP applicant. After these hearings, the LiP felt more confident and satisfied with the judicial style, which provided a more balanced engagement for both parties. As Trinder et al. (2014) mention, any future reforms need to take into account the variety of judicial styles.

Another important stage of family proceedings, when interaction plays a key role, is pre-hearing negotiations with the other party in the waiting area. The standard pattern is for solicitors to offer shuttle negotiations in stages (solicitor-client discussions of outstanding issues, solicitor-solicitor negotiations, solicitor-client discussions, solicitor-solicitor further negotiations, etc) and then update the judge on the progress. Without a legal representative, the pattern of negotiations is different: LiPs face a double role on their own, while the represented party has more time to think about options. In the observed negotiations, the LiP reported feeling isolated and pressured to agree by the solicitor without properly understanding what the proposed settlement was. In one of the negotiations the solicitor even bullied the LiP by 
saying that the LiP should consider the offer and if the offer was declined, they would sue the LiP for legal costs incurred. This left the LiP feeling intimidated and threatened despite the extensive preparations they had made and their general awareness of the fact that in family cases costs orders are very unusual. Their discursive knowledge and powerful institutional status allowed the solicitor to approach the LiP in a way they might not have approached a represented client. The same LiP was approached on a different occasion by a different solicitor representing the same client asking her to consider dropping a criminal charge for domestic violence against their client (domestic violence charges were not connected to the observed financial remedy proceeding, but the previous criminal allegations in the criminal case against and Children Act proceedings) ${ }^{*}$. Although observations of hearings and negotiation during three days of the same case did not present a representative sample, the unethical conduct of the solicitors is worrying. The new guidelines Litigants in person: guidelines for lawyers (2015) will hopefully promote the change towards a more respectful cooperation.

\section{Conclusions}

As Lord Neuberger noted: "Citizens are bearers of rights, they are not simply or merely consumers of services." (LASPO: One year on, 67). Given the level of communicative, legal and procedural challenges involved in representing oneself in court, improving access to justice requires a complex solution. The article illustrates challenges LiPs face during individual stages of financial remedy proceedings. Their lack of capacity is explained by their lack of discursive practice and competence, which has a negative impact on case management for the judiciary and courts. Providing more user-friendly forms, court communication, processes and procedures as well as signposting LiPs to relevant and accurate sources of information and services will contribute to increasing LiPs' trust in the system. Further research is however required on accommodating the needs of LiPs with different forms of vulnerabilities.

\footnotetext{
* The author is fully aware of the fact that, if reported to the SRA, both solicitors could have been suspended or at least reprimanded. In the circumstances of the given case though, it was extremely important to keep a working relationship with the solicitor firm. The author felt that agitating the situation further would not help the family who were going through fully contested proceedings related to divorce, children arrangements, and financial remedy.
} 


\section{Bibliography}

A Guide to Representing Yourself in Court. (2014). The Bar Council. Retrieved from: http://www.barcouncil.org.uk/media/203109/srl_guide_final_for_online_use.pdf.

A Handbook for Litigants in Person. Retrieved from: https://www.judiciary.gov.uk/wpcontent/uploads/JCO/Documents/Guidance/A_Handbook_for_Litigants_in_Person. pdf.

Assy, R. (2011). Can the law speak directly to its subjects? The limitation of plain language. Journal of Law and Society, 38(3), 376-404.

Atkinson, J. M. (1982). Understanding formality: the categorization and production of formal interaction. British Journal of Sociology, 33(1), 86-117.

Bhatia, V. K. (1993). Analysing genre: Language use in professional settings. London: Longman.

Bhatia, V. (2004). Worlds of written discourse: A genre-based view. London and New York: Continuum.

Billett, S. (1996). Situated learning: Bridging sociocultural and cognitive theorising. Learning and Instruction, 6(3), 263-280.

Black, Rt., Cleary, A., \& Culworth, W. (Eds). (2014). The Family Court Practice. Family Law.

Brown, G., \& Yule, G. (1983). Discourse Analysis. Cambridge: Cambridge University Press.

Conley, J. M., \& O’Barr, W. M. (1998). Just Words: Law, Language, and Power. Chicago: University of Chicago.

Coulthard, M., \& Johnson, A. (2007). Introducing Forensic Linguistics: Language in Evidence. New York: Routledge.

Cotterill, J. (2003). Language and Power in Court: A Linguistic Analysis of the O.J. Simpson Trial. Basingstoke: Palgrave Macmillan.

Drew, P., \& Heritage, J. (1993). Analysing Talk at Work, In P. Drew, \& J. Heritage, (eds) Talk at work: Interaction in institutional settings, (pp.3-65). Cambridge: CUP.

Fairclough, N. (1989). Language and Power. London: Longman.

Fielding, N. (2010). Mixed methods research in the real world. International Journal of Social Research Methodology, 13(2), 127-138.

Gibbons, J. (2003). Forensic linguistics: An introduction to language in the legal system. London: Blackwell.

Heffer, C., Rock, F. E., \& Conley, J. (Eds.). (2013). Legal-lay communication: textual travels in the law. Oxford: Oxford University Press. 
Heffer, C. (2005). The Language of Jury Trial: A Corpus-Aided Analysis of Legal-Lay Discourse. Basingstoke: Palgrave Macmillan.

Heydon, G. (2005). The Language of Police Interviewing: A Critical Analysis. Basingstoke: Palgrave Macmillan.

Leggatt, A. (2001). Tribunals for Users - One System, One Service. Retrieved from: http://webarchive.nationalarchives.gov.uk/+/http://www.tribunalsreview.org.uk/leggatthtm/leg-00.htm

Litigants in person: guidelines for lawyers. (2015). Bar Council, CILEx and the Law Society. Retrieved from: https://www.lawsociety.org.uk/Support-services/Advice/Articles/Litigantsin-person-new-guidelines-for-lawyers-June-2015/

Maclean, M. (2014). The changing professional landscape. Family law, 44(2), 177-182.

Moorhead, R., \& Sefton, M. (2005). Litigants in person: Unrepresented litigants in first instance proceedings. London: Department for Constitutional Affairs.

O'Barr W.M. and Conley, J.M. (1990). Litigant Satisfaction versus Legal Adequacy in Small Claims Court Narratives. In Levi, J.N., \& Walker, A.G. (Eds.) Language in the Judicial Process. New York and London: Plenum.

Professional Conduct Department Thematic Review: Complaints Received from Litigants in Person (Self-Represented Litigants). (2012). Bar Standards Board. Retrieved from: https://www.barstandardsboard.org.uk/media/1438061/lip_-_final_version.pdf

Pilnick, A. and Dingwall, R. (2011). On the Remarkable Persistence of Asymmetry in Doctor/Patient Interaction: A Critical Review. Social Science \& Medicine, 72(8), 13741382 .

Raymond, G. (2003). Grammar and Social Organisation: Yes/No Interrogatives and the Structure of Responding. American Sociological Review, 68, 939-967.

Reed, L. (2014). The Family Court Without a Lawyer: A Handbook for Litigants in Person. Bath Publishing Limited.

Sommerlad, H. (2015). Access to Justice in hard times: the deconstruction of democratic citizenship. In Maclean, M., Eekelaar, J., \& Bastard, B. (Eds.). Delivering Family Justice in the 21st Century 2015 (pp. 243-64). Oxford: Hart.

Report of the Financial Remedies Working Group. (2014). Retrieved from: http://www.familylaw.co.uk/news_and_comment/report-of-the-financial-remediesworking-group-31-july-2014\#.VWdzm_RDuSq

The Judicial Working Group on Litigants in Person: Report. (2013). Judicial Office. Retrieved from:https://www.judiciary.gov.uk/publications/judicial-working-group-lip-report/ 
The Legal Aid, Sentencing and Punishment of Offenders Act 2012 (LASPO): One year on. Final Report. (2014). Retrieved from: http://www.barcouncil.org.uk

Thornborrow, J. (2002). Power Talk: Language and Interaction in Institutional Discourse. London: Longman.

Tkacukova, T. (2015, forthcoming). A corpus-assisted study of the discourse marker 'well' as an indicator of institutional roles: Professional and lay use in court cases with litigants in person. Corpora.

Tkacukova, T. (2011). Lay People as Cross-Examiners: A Linguistic Analysis of the Libel Case McDonald's Corporation v. Helen Steel and David Morris. The International Journal of Speech, Language and the Law, 17(2), 307-310.

Tkacukova, T. (2010). Cross-Examination Questioning: Lay People as Cross-Examiners. In Coulthard, M., \& Johnson, A. (Eds.). The Routledge Handbook of Forensic Linguistics. London and New York: Routledge.

Tkachuk, T. (2008). Turn-Taking Management during Cross-Examination: Lay People as Cross-Examiners. Topics in Linguistics: Politeness and Interaction. Nitra: Constantine the Philosopher University, 72-77.

Tkachuk, T. (2007). Linguistic Analysis of Lay Advocacy: Do Lay People Stand a Chance when Representing themselves in Court? Proceedings of the Second European IAFL Conference on Forensic Linguistics / Language and the Law. Barcelona: University Pompeu Fabra, 239-247.

Trinder. L, Hunter, R., Hitchings, E., Miles, J., Moorhead, R., Smith, L., Sefton, M., Hinchly, V., Bader, K. \& Pearce, J. (2014). Litigants in person in private family law cases. . et al. (2014). Litigants in Person in Private Family Law Cases. Ministry of Justice Analytical Series. Retrived from: www.justice.gov.uk/publications/researchand-analysis/moj

Trinch, S. (2005). Acquiring Authority through the Acquisition of Genre: Latinas, Intertextuality and Violence. Speech, Language, and the Law, 12(1), 19-47.

Wang, J. (2006). Questions and the Exercise of Power. Discourse and Society, 17(4), 529-548. Williams, K. (2011). Litigants in person: a literature review. Research summary, 2(11). Zuckerman, A. A. (2014). No Justice Without Lawyers-The Myth of an Inquisitorial Solution. Oxford Legal Studies Research Paper, 66, 355-374.

Acknowledgements 
The research was funded by the European Commission, Marie Curie Intra-European Fellowship for Career Development, proposal number 329925 under the call FP7-PEOPLE2012-IEF, Centre for Forensic Linguistics, Aston University. 